\title{
Commentary: Left subclavian artery revascularization during zone 2 thoracic endovascular aortic repair: Bypass versus transposition? Just do it!
}

\author{
G. Chad Hughes, MD
}

From the Division of Cardiovascular and Thoracic Surgery, Department of Surgery, Duke University Medical Center, Durham, NC.

Disclosures: Author has nothing to disclose with regard to commercial support.

Received for publication May 1, 2019; accepted for publication May 3, 2019; available ahead of print July 4, 2019. Address for reprints: G. Chad Hughes, MD, Box 3051 DUMC, Durham, NC 27710 (E-mail: gchad.hughes@ duke. edu).

J Thorac Cardiovasc Surg 2020;159:1228-30

$0022-5223 / \$ 36.00$

Copyright (c) 2019 by The American Association for Thoracic Surgery

https://doi.org/10.1016/j.jtcvs.2019.05.050

Revascularization of the left subclavian artery (LSA) is almost certainly the most important method available to mitigate the risk of spinal cord ischemia during thoracic endovascular aortic repair (TEVAR) with zone 2 coverage given the unproven benefit of lumbar cerebrospinal fluid drainage in this setting, ${ }^{1,2}$ as well as case reports of spinal cord rescue after TEVAR via urgent LSA revascularization when cerebrospinal fluid drainage failed. ${ }^{3}$

The anatomic reasons for this importance include that the vertebral artery branches of the subclavian arteries join to form the anterior spinal artery (ASA), ${ }^{4}$ which supplies the anterior two-thirds of the spinal cord containing the corticospinal tract responsible for motor function, the spinothalamic tract (pain and temperature), and autonomic tracts (bowel and bladder function). In $90 \%$ of people, the ASA diminishes in size as it travels distally along the spinal cord, ${ }^{5}$ which explains why the lower thoracic or thoracolumbar cord is at risk during descending thoracic and thoracoabdominal aortic repair. Perfusion to the ASA is augmented distally primarily by the great anterior radicular artery, or artery of Adamkiewicz, which usually $(85 \%)$ arises from the left-hand side of the thoracoabdominal aorta; the level of origin is T9-12 in 75\% of cases, although it may arise higher (T5-8; 15\%) or lower (L1-2; 10\%) in some individuals. ${ }^{6}$ As evidenced by the low rates of spinal cord ischemia reported after TEVAR, ${ }^{7}$ coverage of the artery of Adamkiewicz is usually well tolerated because of collateral pathways to this vessel. The LSA is important in this regard as well and represents the primary source of collateral pathways to the artery of Adamkiewicz outside of the spinal column via the thoracodorsal artery (Figure 1, A) and internal thoracic artery (Figure 1, B). ${ }^{8}$

The Society for Vascular Surgery published practice guidelines in 2009 regarding management of the LSA with TEVAR $^{9}$ and recommended routine preoperative revascularization in all elective cases requiring LSA coverage. Our group has previously published on the safety of a selective LSA revascularization strategy, ${ }^{10}$ although in

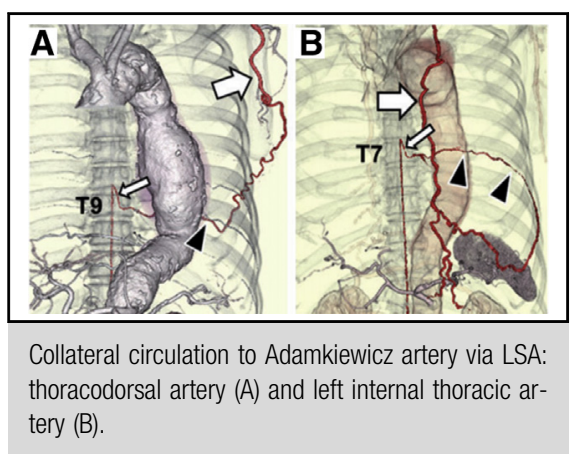

Central Message

LSA revascularization is the most important way to mitigate spinal cord ischemia during TEVAR. Whether bypass or transposition, one should revascularize the LSA whenever covered.

See Article page 1222.

practice we revascularize the LSA essentially $100 \%$ of the time when it is fully covered with little to no preservation of antegrade flow. ${ }^{11}$ It should be noted that, in many cases, the LSA can be only partially covered so as to gain additional proximal seal, yet without significant interruption of antegrade flow. ${ }^{7}$ Our practice is to place bilateral radial arterial lines in all cases where either full or partial LSA coverage is planned, ${ }^{10}$ and for those cases with partial coverage, to confirm preservation of left radial arterial line pulsatility after endograft deployment. Intraoperative neurophysiologic monitoring with motor- and sensory-evoked potentials is likewise used ${ }^{12}$ and should remain intact after partial LSA endograft coverage. If either of these criteria are not met, then we would proceed to revascularize the LSA in the partial coverage setting.

In the current issue of the Journal, Bianco and colleagues $^{13}$ from the University of Pittsburgh report their experience with left subclavian to carotid transposition for LSA revascularization during zone 2 TEVAR. Unlike most centers, the authors use transposition, rather than bypass, as their preferred mode of LSA revascularization in this setting. They performed this operation in 58 patients with low rates of bypass specific morbidity $(2 \%$ recurrent laryngeal nerve injury, $2 \%$ chyle leak) and 100\% transposition patency on follow-up computed tomography angiography imaging. 

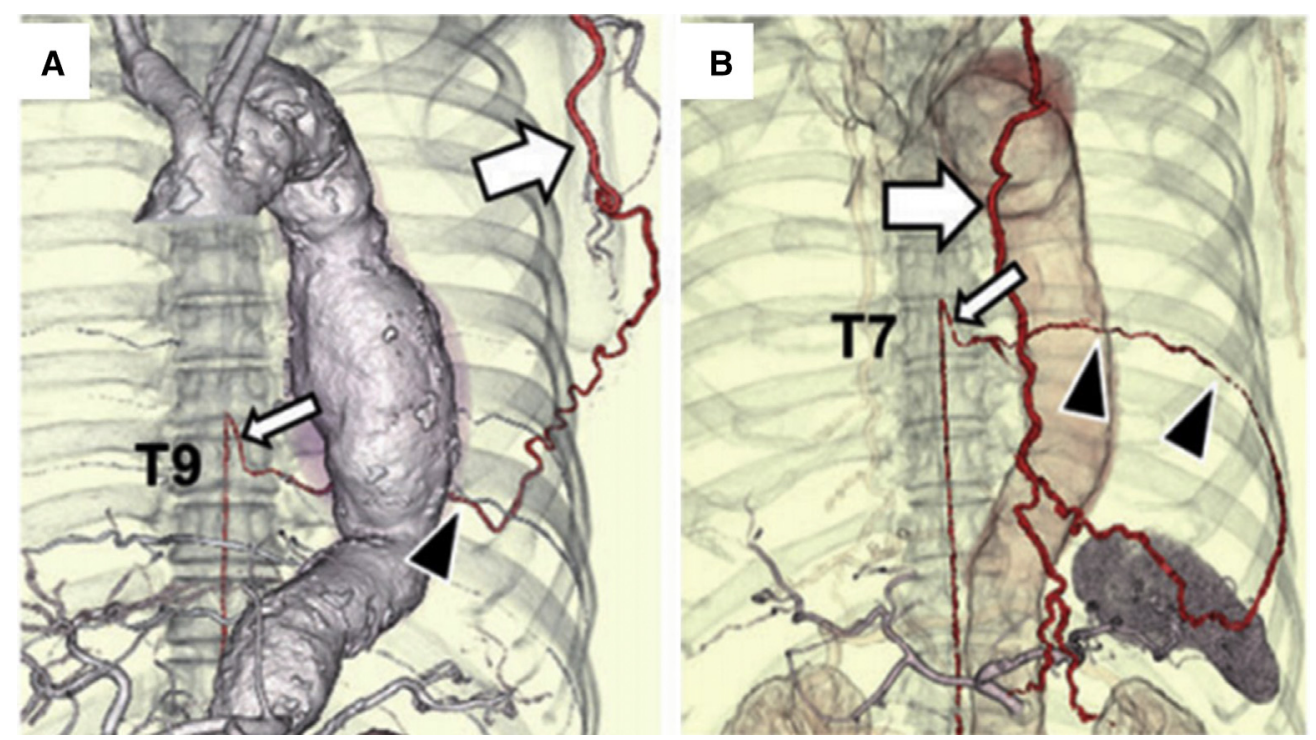

FIGURE 1. Collateral circulation (black arrowheads) to Adamkiewicz artery (small white arrows) via LSA; thoracodorsal artery (A; large white arrow) and left internal thoracic artery (B; large white arrow).

The authors cite several potential advantages of transposition over bypass, including the avoidance of prosthetic material and the avoidance of type II endoleak presuming the LSA is ligated proximally at the arch. These seem like reasonable assertions, although our group found no wound or graft infections in a larger series $(\mathrm{n}=112)$ of carotidsubclavian bypass procedures performed using polytetrafluoroethylene grafts in the setting of zone 2 TEVAR. ${ }^{11}$ Likewise, type II endoleak is easily avoided in the scenario of bypass using endovascular means such as occlusion plugs or coils, which we have done routinely for the past 15 years. Further, ligation of the LSA at the aortic arch as required to prevent type II endoleak with transposition becomes increasingly challenging in the setting of morbid obesity or vessel fragility, which is a common finding due to the thin-walled nature of the supraclavicular LSA.

Finally, the authors have failed to mention one major contraindication to transposition, which is the scenario where a patient has a patent left internal thoracic artery bypass graft upon which he/she is dependent for coronary flow. In this scenario, which was the indication for LSA revascularization in $9 \%$ of patients in our series, ${ }^{11}$ the patient will be at risk for myocardial ischemia due to the mandatory period of proximal LSA occlusion during clamp and anastomosis to the left common carotid artery. This can likewise be said about a "dominant" left vertebral artery, although this risk is almost certainly less due to more abundant collateral pathways to the brain. ${ }^{14}$ One likely advantage of transposition over bypass is probable superior long-term patency with transposition $(100 \%$ in the current Pittsburgh series vs $97 \%$ for bypass in the Duke series), and we preferentially use transposition in the setting of a young patient undergoing zone 2 TEVAR for this reason.

In summary, transposition represents a reasonable alternative to bypass for LSA revascularization in the setting of zone 2 TEVAR and is likely preferred in the occasional young patient undergoing this procedure; transposition should be approached with caution in the setting of a patent left internal thoracic artery graft because of the risk of myocardial ischemia. In general, one should use whichever procedure he/she is most comfortable with, but most importantly should "just do it" and revascularize the LSA any time it is fully covered. Given that the artery of Adamkiewicz may arise as far proximally as T5 in $15 \%$ of cases ${ }^{6}$ and that the LSA is the most important source of collateral flow to this vessel outside of the spinal column, this guideline should apply even in the scenario of short segment coverage.

\section{References}

1. Wong CS, Healy D, Canning C, Coffey JC, Boyle JR, Walsh SR. A systematic review of spinal cord injury and cerebrospinal fluid drainage after thoracic aortic endografting. J Vasc Surg. 2012;56:1438-47.

2. Hanna JM, Andersen ND, Aziz H, Shah AA, McCann RL, Hughes GC. Results with selective preoperative lumbar drain placement for thoracic endovascular aortic repair. Ann Thorac Surg. 2013;95:1968-75.

3. Borghese O, Sbenaglia G, Giudice R. Late-onset paraplegia after endovascular repair of type B aortic dissection managed by urgent left subclavian artery revascularization: a case report. Ann Vasc Surg. 2019;58:384.e9-14.

4. Miyasaka K, Asano T, Ushikoshi S, Hida K, Koyanagi I. Vascular anatomy of the spinal cord and classification of spinal arteriovenous malformations. Interv $\mathrm{Neu}$ roradiol. 2000;6(Suppl 1):195-8.

5. N'da HA, Chenin L, Capel C, Havet E, LeGars D, Peltier J. Microsurgical anatomy of the Adamkiewicz artery-anterior spinal artery junction. Surg Radiol Anat. 2016;38:563-7.

6. Lazorthes G, Gouazé A, Zadeh JO, Santini JJ, Lazorthes Y, Burdin P. Arterial vascularization of the spinal cord. Recent studies of the anastomotic substitution pathways. J Neurosurg. 1971;35:253-62. 
7. Ranney DN, Cox ML, Yerokun BA, Benrashid E, McCann RL, Hughes GC Long-term results of endovascular repair for descending thoracic aneurysms. $J$ Vasc Surg. 2018;67:363-8.

8. Yoshioka K, Tanaka R, Takagi H, Ueyama Y, Sugawara T, Chiba T, et al. Systematic evaluation of collateral pathways to the artery of Adamkiewicz using computed tomography. Eur J Cardiothorac Surg. 2018:54:19-25.

9. Matsumura JS, Lee WA, Mitchell RS, Farber MA, Murad MH, Lumsden AB, et al. The Society for Vascular Surgery practice guidelines: management of the left subclavian artery with thoracic endovascular aortic repair. J Vasc Surg. 2009:50:1155-8.

10. Lee TC, Andersen ND, Williams JB, Bhattacharya SD, McCann RL, Hughes GC. Results with a selective revascularization strategy for left subclavian artery coverage during thoracic endovascular aortic repair. Ann Thorac Surg. 2011;92:97-103.
11. Voigt SL, Bishawi M, Ranney D, Yerokun B, McCann RL, Hughes GC. Outcomes of carotid-subclavian bypass performed in the setting of thoracic endovascular aortic repair. J Vasc Surg. 2019;69:701-9.

12. Husain AM, Swaminathan M, McCann RL, Hughes GC. Neurophysiologic intraoperative monitoring during endovascular stent graft repair of the descending thoracic aorta. J Clin Neurophysiol. 2007;24:328-35.

13. Bianco V, Sultan I, Kilic A, Aranda-Michel E, Cuddy RJ, Srivastava A, et al. Concomitant left subclavian artery revascularization with carotid-subclavian transposition during zone 2 thoracic endovascular aortic repair. J Thorac Cardiovasc Surg. 2020;159:1222-7.

14. Matalanis G, Galvin SD. "Branch-first" continuous perfusion aortic arch replacement and its role in intra-operative cerebral protection. Ann Cardiothorac Surg. 2013;2:194-201. 